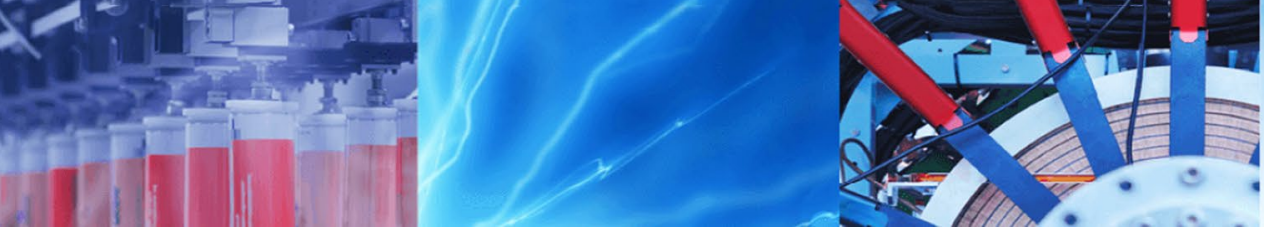

Research Article

\title{
Chitosan-PEO nanofiber mats for copper removal in aqueous solution using a new versatile electrospinning collector
}

\author{
Ilse lleana Cardenas Bates ${ }^{1} \cdot$ Éric Loranger $^{1} \cdot{\text { Bruno } \text { Chabot }^{1}}^{10}$
}

Received: 20 June 2020 / Accepted: 13 August 2020 / Published online: 20 August 2020

(c) Springer Nature Switzerland AG 2020

\begin{abstract}
Electrospun chitosan-polyethylene oxide nanofiber mats were fabricated using a new collector design. Besides being reusable, it allows to assess the desired morphology of the mat in a quicker way. To test its efficiency, nonwoven mats designed for water treatment applications were prepared using conditions never been reported before. Under these conditions, continuous and flawless nanofibers of $151 \pm 36 \mathrm{~nm}$ in diameter were achieved. Adsorption capacity of the mats for copper ions in aqueous solutions were investigated. Results showed that sorption equilibrium was achieved within 150 min with a homogenous distribution of copper ions within the nanofibrous mats. The pseudo-second order kinetic model best fitted the experimental data. The Langmuir isotherm best described the sorption process with a maximum adsorption capacity of $124 \mathrm{mg} / \mathrm{g}$ for trial temperatures ranging from 25 to $60^{\circ} \mathrm{C}$. Thermodynamic parameters $\left(\Delta \mathrm{G}^{\circ}, \Delta \mathrm{H}^{\circ}\right.$ and $\Delta \mathrm{S}^{\circ}$ ) demonstrate that the adsorption was feasible, endothermic and spontaneous. The desorption potential and mat's reusability were also studied. Results reveal that the electrospun chitosan mats can be desorbed and reused up to 5 cycles without significant loss in adsorption performance.
\end{abstract}

Keywords Water purification - Chitosan electrospun nanofibers - Electrospinning collector - Copper ions adsorption . Sorbent reusability

\section{Introduction}

Water contamination, especially by toxic heavy metals, has become a major concern over the last decades around the world [1-3]. This is particularly the case in developing and fast-growing countries where rapid industrialization increases demand for water with clear effects on the supply of safe drinking water and access to adequate sanitation services for the population [4, 5]. In such cases, heavy metal wastewaters are in some way discharged into the environment. This is a serious problem as heavy metals are not biodegradable, very toxic and have a carcinogenic effect in living organisms where they can be accumulated [6-8]. Among them, copper ions are frequently detected in waste streams and natural waters, since it is widely used in electrical, machinery, semiconductor, and many other industries. Extensive studies have demonstrated that copper ions discharged into the water can cause serious detrimental effects to human health of which mainly cirrhosis, vomit and central nervous system-related effects $[9,10]$.

To limit those negative impacts, industries need to reduce their pollution loads before wastewater discharge into the environment. Therefore, appropriate treatment technologies must be used. Numerous techniques are available from which the adsorption process is among the most effective thanks to its simplicity, easy handling and economic feasibility, providing high efficiency to remove heavy metals from water [7, 11]. Among the current adsorbents, activated carbon is extensively used because of its versatility and high adsorption capacity owing to its wide surface area [10,12].

Bruno Chabot, Bruno.Chabot@uqtr.ca| 'Institut d'Innovations en Écomatériaux, Écoproduits et Écoénergies, Université du Québec à Trois-Rivières, 3351 boul. des Forges, C.P. 500, Trois-Rivières, QC G9A-5H7, Canada. 
However, it suffers from expensive regeneration and it possesses a high affinity toward organic molecules, which leads to plugging of internal pores and, therefore incomplete adsorption towards contaminants [13]. Therefore, the search for low-cost adsorbents has intensified in recent years. These materials are described as those usually available at free cost and abundant in nature [10].

Chitosan (CS) is the world's third most abundant natural polymer [1]. It is produced from chitin found in the residues of the crabbing industry. Due to the abundance and availability of this waste product, it is potentially a cheaper solution to current adsorbents available on the market. It is also biodegradable, biocompatible, antimicrobial and compostable $[14,15]$. The presence of amino and hydroxyl groups in the polymer backbone allows the chelation of metals and their adsorption from the water phase $[1,6,16]$. Among the chitosan-based materials (nanoparticles, gel beads, membranes, mats, sponges, fibers or hollow fibers) $[17,18]$, chitosan nanofiber mats obtained by electrospinning are an attractive way to remove pollutants from aqueous solutions. This is mostly due to the nanometric diameter size of the resulting fibers providing structural advantages $[9,19]$. However, the optimization of the process in this technique is time consuming. At least 10 parameters may have major effects on morphology of the material [20]. One of them is the collector type, as it possesses a strong influence on the productivity and disposition of the nanofibers and the nonwoven structure collected. There are two types of collectors, rotating and static [21]. At laboratory scale, when using these collectors, an aluminum foil is wrapped over the collector which is removed at the end of the process along with the nanofibers $[5,18,21-26]$. However, the nanofibers remain attached to the aluminum foil, making it difficult to recover them. This is time-consuming and can lead to a loss of material, as not all the fibers can be completely recovered. In addition, aluminum waste is generated. For this reason, one of the purposes of this research is to develop an electrospun nanofiber sorbent material using a new timesaving type of collector, which provides several advantages compared to the current ones. Also, new electrospinning conditions were assessed to obtain good nanofibrous mat's structural properties as well as adsorption capacity toward copper ions from aqueous solutions. Desorption trials with various eluents were also carried out to ensure the reusability of the nanofibrous mats and estimate their potential impact for the protection of the environment.

\section{Materials and methods}

\subsection{Materials}

The chitosan used at low molecular weight had a deacetylation degree of $75-85 \%$. Polyethylene oxide (PEO) was used as a co-spinning agent and its average molecular weight was $\mathrm{Mv} \sim 900,000$. Concentrated acetic acid (99.7\%) was used to dissolve the chitosan powder. Copper sulfate pentahydrate $\left(\mathrm{CuSO}_{4} \cdot 5 \mathrm{H}_{2} \mathrm{O}\right)$ was used as a model contaminant for adsorption testing. All chemicals were supplied by Sigma-Aldrich (USA) without additional purification. Ethylenediamine tetraacetic acid (EDTA) powder ( $99 \%$ A.C.S., OMEGA chemical company, USA) was used for the titration of copper ions in the presence of Murexide as the indicator. Sodium carbonate $\left(\mathrm{Na}_{2} \mathrm{CO}_{3}\right)$ was also used for nanofiber neutralization. Distilled water was used for preparing each of the solutions.

\subsection{Preparation of CS-PEO solution}

Chitosan, which is commonly dissolved in acetic acid, is known to be difficult to electrospin alone, due to its high viscosity and surface tension. Some publications [25, $27,28]$ have reported electrospinning of chitosan alone by dissolving it in Trifluoro acetic acid (TFA) or Dichloromethane (DCM). However, these solvents, beyond being toxic, are carcinogenic; therefore, their use is not recommended. To solve this problem, chitosan is generally blended with PEO which is a synthetic nontoxic polymer and easily electrospinnable $[29,30]$.

For this reason, a solution of $1.5 \mathrm{wt} \%$ PEO dissolved in distilled water and a solution of $2.5 \mathrm{wt} \%$ chitosan dissolved in acetic acid ( $90 \% \mathrm{v} / \mathrm{v})$ were prepared individually. Both solutions were kept agitated at $23^{\circ} \mathrm{C}$ for $20 \mathrm{~h}$ to ensure complete and homogeneous dissolution. Subsequently, these solutions were mixed at a ratio of $4: 3$ by weight of CS/PEO and the resulting solution was magnetically stirred for $2 \mathrm{~h}$. Then, the mixture was placed in an ultrasonic bath for $15 \mathrm{~min}$ to remove air bubbles. Finally, the mixture was kept at rest for $3 \mathrm{~h}$ before being used in the electrospinning system.

\subsection{Nanofibrous mat preparation}

The polymeric solution was introduced into a $5 \mathrm{~mL}$ syringe fitted with a 20 Gauge (Kimble chase, Gerreshimer) blunt stainless-steel needle. The solution was electrospun using a horizontal electrospinning set-up as shown in Fig. 1. The system was equipped with a 
Fig. 1 Schematic diagram of the electrospinning set-up

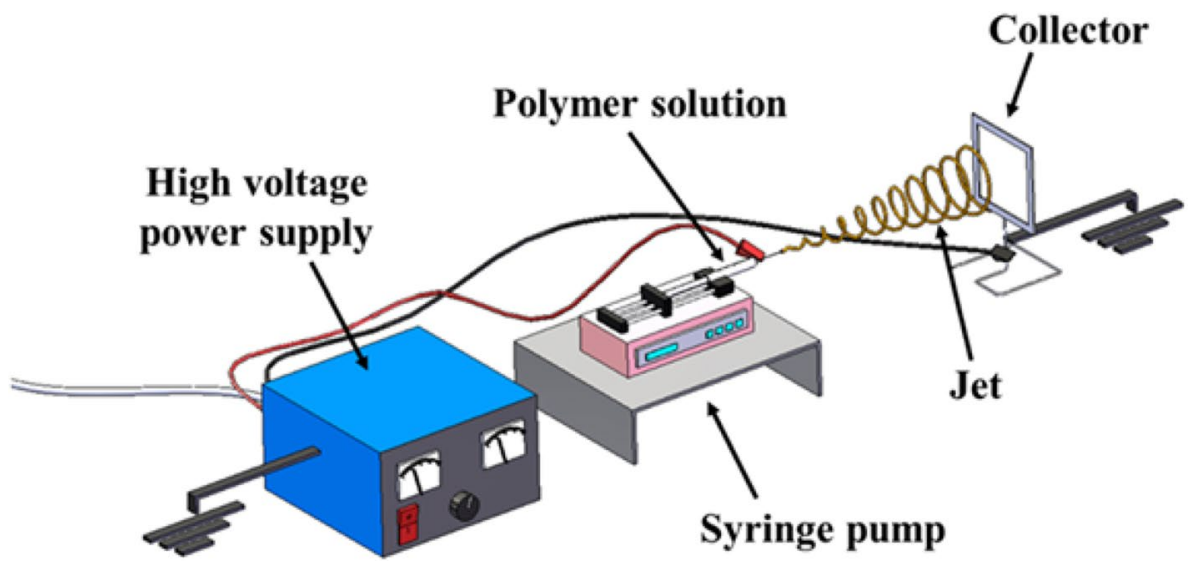

programmable pump (KD scientific, model 100), a high voltage-power supply (Gamma High Voltage Research, USA) and a metallic wireframe as a new type of collector.

Electrospun CS/PEO fibers were fabricated using the following conditions:

- Voltage: $12-14 \mathrm{kV}$

- Feed rate: $0.6 \mathrm{~mL} / \mathrm{h}$

- Distance between needle and collector: $12 \mathrm{~cm}$

- Needle diameter: $0.6 \mathrm{~mm}$ I.D.

At the end of the electrospinning process, the nanofibrous mat was removed from the frame and dried in an oven at $75^{\circ} \mathrm{C}$ for $24 \mathrm{~h}$. Then, the nanofibers were neutralized with a solution of $\mathrm{Na}_{2} \mathrm{CO}_{3} 0.1 \mathrm{M}$ for $3 \mathrm{~h}$ in order to hold their morphology in aqueous solution. The mat was then washed with distilled water until the $\mathrm{pH}$ of the wash water was 6 and finally dried at room temperature [31].

\subsection{Characterization of CS-PEO nonwoven mats}

To study the morphology of nanofibers, images of the mat at different magnifications were taken using a JEOL-JSM 5500 scanning electron microscope (SEM) at a voltage of $15 \mathrm{kV}$ after gold coating pretreatment. The nanofiber's average diameter was measured using an image processing software [32] from a minimum of 100 nanofibers per sample. The dispersion analysis and the chemical quantification of the elements were carried out by X-ray energy dispersion (EDX) Oxford instrument X-Max $20 \mathrm{~mm}^{2}$.

\subsection{Batch adsorption experiments}

Chitosan has a stronger ability to adsorb $\mathrm{Cu}^{2+}{\text { from } \mathrm{CuSO}_{4}}$ compared to other salts [33]. Therefore, copper solutions at predetermined concentrations were prepared by diluting anhydrous copper sulfate in distilled water. Subsequently, batch adsorption tests were performed to study copper adsorption by stirring $25 \mathrm{mg}$ of mat sample into $50 \mathrm{~mL}$ of the copper solution at $200 \mathrm{rpm}$ and $\mathrm{pH}$ 6.0. The quantity of copper ions adsorbed was calculated according to the following equation:

$q_{e}=\left(C_{0}-C_{e}\right) \frac{V}{m}$

where $q_{e^{\prime}}$ copper uptake at equilibrium $(\mathrm{mg} / \mathrm{g}) ; C_{0}$, initial copper concentration (mg/L); $C_{e^{\prime}}$ copper concentration at equilibrium (mg/L); $V$, volume of solution $(\mathrm{L}) ; m$, mass of the sorbent (mg).

After equilibrium, the copper concentration remaining in the aqueous phase was determined by a titration technique [34]. Then, the mat was rinsed with distilled water and dried at room temperature for further analyses. All the experiments were performed in triplicate.

\subsection{Kinetic analysis}

Adsorption kinetic studies were carried out at room temperature with an initial concentration of $100 \mathrm{ppm}$ of copper ions. At intervals of $30 \mathrm{~min}, 2 \mathrm{~mL}$ samples were taken from the flask and the concentration of copper was determined by titration. In order to elucidate the adsorption mechanism involved, non-linear pseudo-first order (Eq. 2), non-linear pseudo-second order (Eq. 3) and intraparticle diffusion (Eq. 4) models were used to fit experimental data as they are the most widely tested models for the sorption of copper ions from wastewater $[6,35$, $36]$. Such kinetic models are used to analyse the type of mechanism involved during the adsorption process as well as the role of the adsorption surface, the chemical reaction involved, and/or diffusion mechanisms. The pseudo-first order model supposes physical adsorption as the mechanism of prevalence, while the pseudo-second order model assumes chemical adsorption. Intraparticle diffusion model was developped by Weber and Morris in order to explain the intraparticle diffusion by correlating 
adsorption capacity to effective diffusivity of the adsorbate within the adsorbent material [37].

$q_{t}=q_{e}\left(1-\exp ^{-k_{1} t}\right)$

$q_{t}=\frac{k_{2} q_{e}^{2} t}{1+k_{2} q_{e} t}$

$q_{t}=k_{i d} t^{1 / 2}+C$

where $q_{e^{\prime}}$ amount adsorbed $(\mathrm{mg} / \mathrm{g})$ at equilibrium; $q_{t^{\prime}}$ amount adsorbed $(\mathrm{mg} / \mathrm{g})$ at time $\mathrm{t}(\mathrm{min}) ; k_{1}$, pseudo first order adsorption rate constant $\left(\mathrm{min}^{-1}\right) ; k_{2}$, pseudo second order adsorption rate constant $(\mathrm{g} /(\mathrm{g} \mathrm{min})) ; k_{i d}$ intraparticle diffusion rate constant $\left(\mathrm{g} /\left(\mathrm{g} \mathrm{min}{ }^{1 / 2}\right)\right) ; C$, thickness of the boundary layer $(\mathrm{mg} / \mathrm{g})$.

\subsection{Equilibrium isotherms}

Equilibrium isotherms were carried out at $25^{\circ} \mathrm{C}, 45^{\circ} \mathrm{C}$ and $60^{\circ} \mathrm{C}$ for initial copper concentrations ranging from 25 to $150 \mathrm{ppm}$. After $3 \mathrm{~h}, 2$ samples of $2 \mathrm{~mL}$ were taken from the flasks and copper concentrations were determined by titration. Preliminary trials have shown that adsorption equilibrium was achieved after $3 \mathrm{~h}$. In this work, three isotherm models were evaluated: Langmuir, Freundlich and Dubinin-Radushkevich (D-R) to study the adsorption behavior. The Langmuir isotherm model assumes a monolayer adsorption onto a homogeneous surface where the adsorbed molecules do not interact, and the binding sites have a uniform affinity and energy. The non-linear expression of this isotherm is represented by Eq. (5) [38]:

$q_{e}=q_{m} k_{L} \frac{C_{e}}{1+k_{L} C_{e}}$

where $q_{m}$, maximum adsorption capacity $(\mathrm{mg} / \mathrm{g}) ; k_{L}$, Langmuir constant $(\mathrm{L} / \mathrm{mg}) ; q_{e}$ equilibrium copper uptake on the adsorbent $(\mathrm{mg} / \mathrm{g}) ; C_{e^{\prime}}$ copper concentration at equilibrium (mg/L).

On the other hand, the Freundlich model is based on the assumption of multilayer adsorption on a heterogeneous surface, and the amount adsorbed increases infinitely as the concentration increases. The non-linear model can be described by Eq. (6) [39]:

$q_{e}=k_{F} C_{e}^{1 / n}$

where $n$, adsorption intensity constant; $k_{F}$, Freundlich constant $(\mathrm{mg} / \mathrm{g}) ; q_{e}$, equilibrium copper uptake on the adsorbent $(\mathrm{mg} / \mathrm{g}) ; C_{e}$, copper concentration at equilibrium (mg/L).
Finally, the non-linear $\mathrm{D}-\mathrm{R}$ isotherm model is usually expressed as follows [40]:

$q_{e}=q_{D-R} e^{\left(-\beta \varepsilon^{2}\right)}$

where $q_{e^{\prime}}$ quantity of solute adsorbed per unit mass of adsorbent (mol/g); $q_{D-R^{\prime}}$ maximum adsorption capacity $(\mathrm{mol} / \mathrm{g}) ; \beta$, activity coefficient related to free adsorption energy $\left(\mathrm{mol}^{2} / \mathrm{J}^{2}\right) ; \varepsilon$, Polanyi's potential $(\mathrm{J} / \mathrm{mol})(\varepsilon=R T \mathrm{In}$ $[1+1 / \mathrm{Ce}]) ; R$, gas constant $(\mathrm{R}=8.314 \mathrm{~J} /(\mathrm{mol} \mathrm{K})) ; T$, absolute temperature $(\mathrm{K}) ; C_{e}$ copper concentration at equilibrium (mol/L).

This isotherm model is normally applied to determine the nature of the adsorption process by calculating the activation energy $(E)$ defined as the minimum energy needed for a particular adsorbate-adsorbent interaction and can be determined accordingly to Eq. (8) [41]. This value refers to the energy needed to transfer an adsorbate molecule to the surface of the adsorbent from infinite distance in the solution.

$E=\frac{1}{\sqrt{2 \beta}}$

If $E<8 \mathrm{~kJ} / \mathrm{mol}$, the adsorption is rather considered as physical. Nevertheless, adsorption is presumed as chemical if $8 \mathrm{~kJ} / \mathrm{mol}<\mathrm{E}<16 \mathrm{~kJ} / \mathrm{mol}$ [42].

\subsection{Thermodynamic analysis}

In order to study the spontaneity and feasibility of the process, thermodynamic parameters were determined by calculating the values of Gibbs free energy $\left(\Delta G^{\circ}\right.$, $\left.\mathrm{J} \mathrm{mol}^{-1}\right)$, entropy change $\left(\Delta S^{\circ}, \mathrm{J} \mathrm{mol}^{-1} \mathrm{~K}^{-1}\right)$ and enthalpy change $\left(\Delta H^{\circ}, \mathrm{J} \mathrm{mol}^{-1}\right)$ conforming to the following equations $[43,44]$ :

$\Delta G^{\circ}=-R \operatorname{Tn}\left(K_{c}\right)$

$K_{c}=\frac{q_{e}}{C_{e}}$

$\ln K_{c}=-\frac{\Delta \mathrm{H}}{R T}+\frac{\Delta S}{T}$

$\Delta G^{\circ}$ at various temperatures is determined from Eq. (9), where $K_{c}$ is the constant of equilibrium adsorption. Enthalpy and entropy are obtained from the slope, $\Delta H^{\circ} / R$ and the intercept $\Delta S^{\circ} / R$ by plotting $\ln K_{c}$ versus $1 / T$ according to Van't Hoff equation Eq. (11). 
Table 1 Desorption trials with various eluents and conditions

\begin{tabular}{lll}
\hline Eluent & Concentration (M) & Ratio (v:v) \\
\hline $\mathrm{NaCl}$ & 4.6 & - \\
$\mathrm{NaOH}$ & 1 & - \\
$\mathrm{HCl}$ & 0.01 & - \\
$\mathrm{H}_{2} \mathrm{SO}_{4}$ & 0.1 & - \\
EDTA & 0.00025 & - \\
EDTA-NaOH & $0.001 / 1$ & $1: 0.0028$ \\
EDTA-HCl & $0.001 / 0.5$ & $1: 0.0028$ \\
\hline
\end{tabular}

Table 2 Experimental conditions used to prepare mixture ratios of EDTA-NaOH to achieve targeted $\mathrm{pH}$

\begin{tabular}{llll}
\hline Test & $\mathrm{V}_{\mathrm{NaOH}}(\mu \mathrm{L})$ & Ratio $(\mathrm{v} / \mathrm{v})$ & $\mathrm{pH}$ \\
\hline 1 & 35 & $1: 0.0007$ & 6.5 \\
2 & 70 & $1: 0.0015$ & 7 \\
3 & 105 & $1: 0.0021$ & 7.5 \\
4 & 140 & $1: 0.0028$ & 8 \\
5 & 175 & $1: 0.0035$ & 8.5 \\
\hline
\end{tabular}

EDTA conc.: $0.0001 \mathrm{M}$; $\mathrm{NaOH}$ conc.: $1 \mathrm{M}$; volume EDTA: $50 \mathrm{~mL}$

\subsection{Reusability study}

After sorption, CS-PEO mats were rinsed with deionized water and dried overnight at room temperature. Desorption experiments were performed under batch conditions using various eluents and concentrations as indicated in Table 1. After desorption, the mats were rinsed with deionized water and dried at room temperature for subsequent adsorption/desorption cycles.

The effect of eluent $\mathrm{pH}$ was then studied using various EDTA-NaOH mixture ratios as shown in Table 2. From both series of experiments, percentage recoveries of copper, as well as weight losses of mats were recorded after soaking time.

\section{Results and discussion}

\subsection{Preparation of CS-PEO nonwoven nanofibrous mats}

A typical electrospinning set-up contains a syringe, a high voltage-power supply, and an aluminum foil as a collector. The syringe is filled with the polymeric solution which is then pushed out using a pump at a controlled rate. In order to create an electric field, the metallic needle of the syringe must be connected to a high voltage-power supply along with the grounded collector where the nanofibers will be deposited during the electrospinning process.
When it is a question of manufacturing a new nanofiber membrane or an existent membrane under different conditions, the optimization process of the parameters must be clearly first carried out. During this stage, it is very common to observe the formation of solid particles (caused by electrospraying) or a combination of particles and fibers (electrospraying/electrospinning effect) before achieving continuous and flawless fibers which will further form a nonwoven mat (Fig. 2). However, these two electrohydrodynamic processes cannot be easily distinguished at naked eye as both lead into a nano-morphological material. Thus, every time a material is produced, the use of the scanning electron microscope is essential to determine the morphology obtained. This is a time-consuming and expensive process. For this reason, we have designed a new collector in the form of a metallic wire-frame that allows to identify in a faster way the morphology of the collected material; particles, fibers or particles/fibers (Fig. 3). Since the central part of the wire-frame collector is empty, if an electrospraying process occurs, the charged particles will be pulled into the electric field towards the metallic part of the collector and therefore deposited only over the frame as shown in Fig. 3a. On the contrary, when an electrospinning process takes place, a nanofiber web starts to build up at the corners of the frame due to the larger surface area in there, which leads to the build-up of surface charges (Fig. 3b). The deposition process will continue until a mesh covers completely the empty space within the frame as a "spider's web" as shown in Fig. 3c. Furthermore, this collector also allows to quickly identify if a combination of an electrospraying/electrospinning process is occurring since even if some nanofibers are deposited, the particles can break them, preventing or reducing the formation of the mat. Hence, this new collector system provides several advantages compared to the standard aluminum foil generally used in electrospinning set-up. The most important advantages are its reusability, an easier mat recovery process using a simple cutter, and a faster way to determine the morphology of the collected material.

\subsection{Characterization of CS-PEO nonwoven nanofibrous mats}

The morphological characteristics of CS/PEO electrospun mat and the nanofiber's diameter size distribution are presented in Fig. 4a, b, respectively. The SEM image shows uniform and continuous nanofibers with an average diameter of $151 \pm 36 \mathrm{~nm}$. This relatively small diameter should provide a high specific surface area, with more $\mathrm{NH}_{2}$ groups on the surface. If those groups are available for copper ions, a high adsorption capacity is expected. 
Fig. 2 Polymeric solution electrodeposited over an aluminum foil with three different morphological possibilities having the same appearance at naked eye
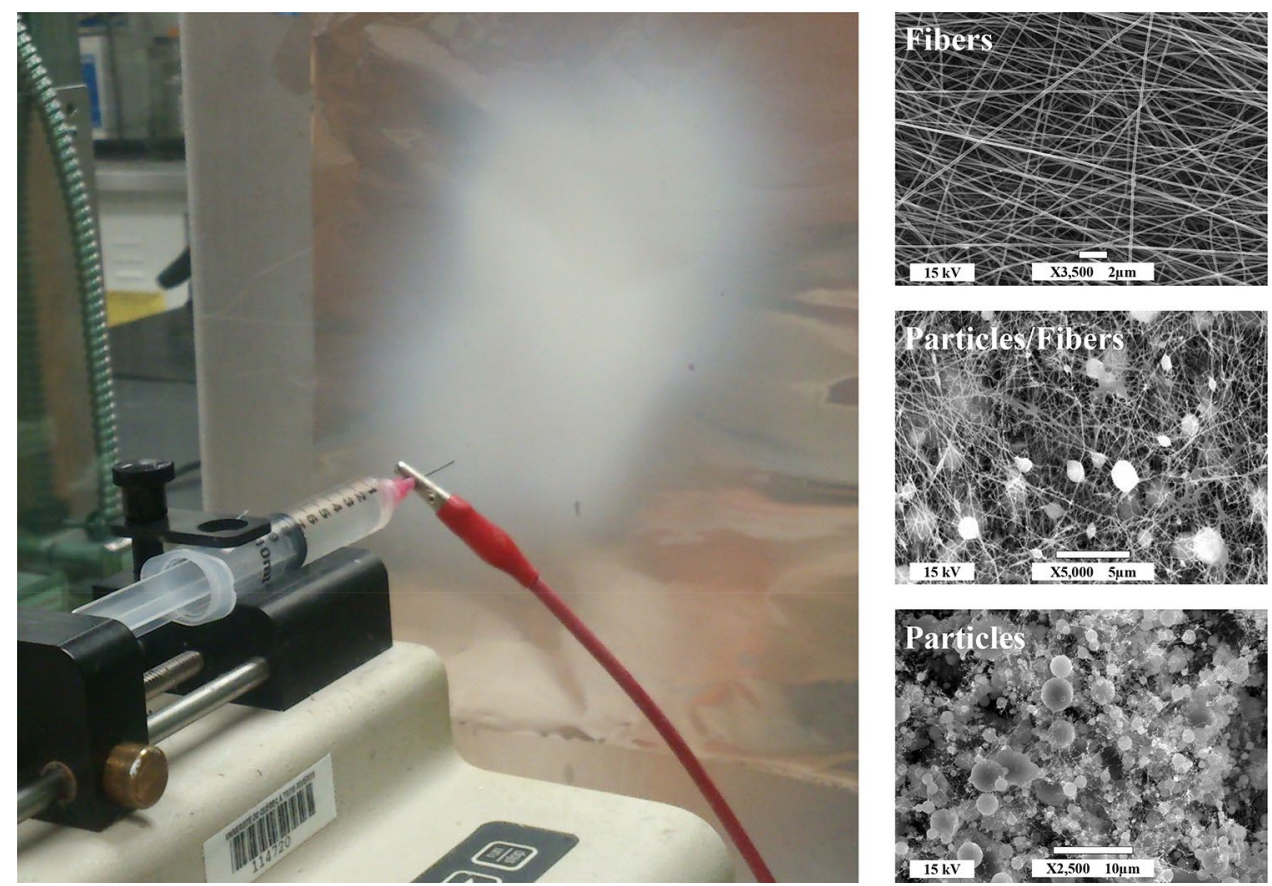

Fig. 3 Effect of electrospraying (a) and electrospinning at the beginning of the process (b) and at the end (c), using the wire-frame collector
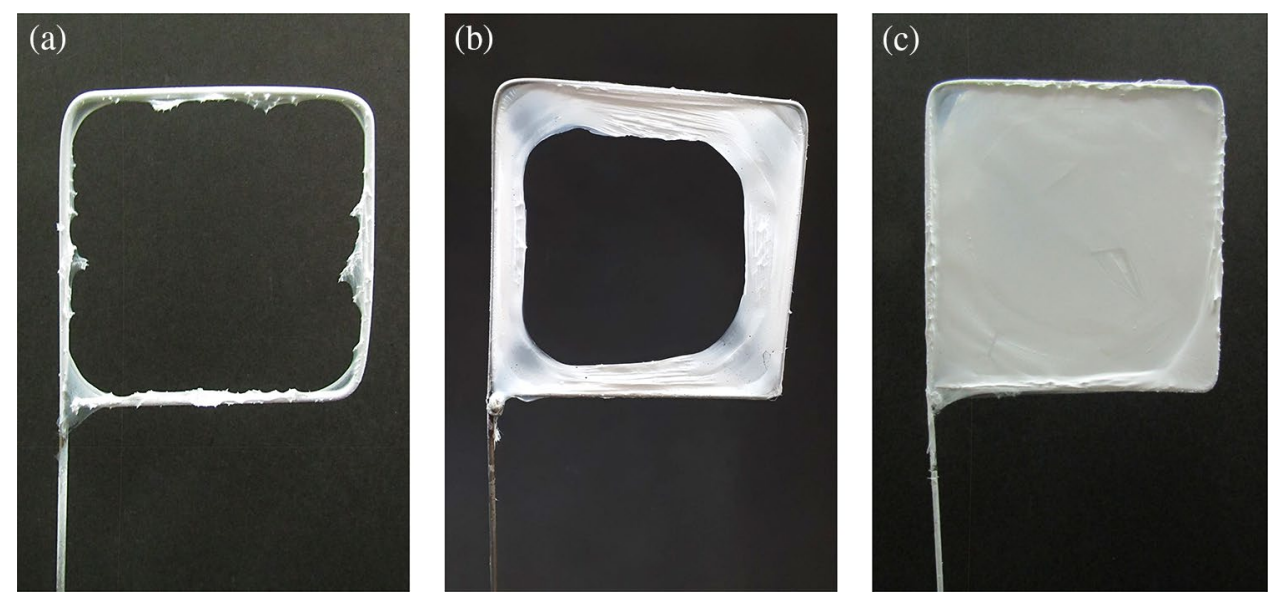
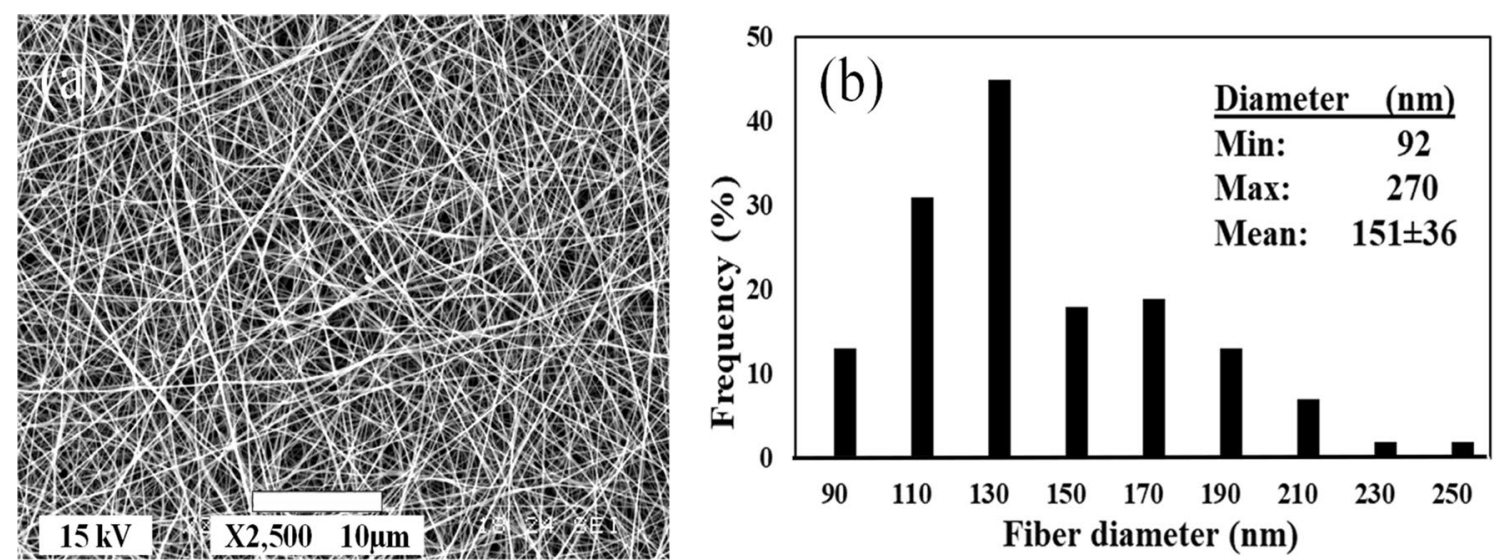

Fig. 4 a Scanning electron micrograph and $\mathbf{b}$ diameter distribution of native CS/PEO electrospun nanofibers (4:3 ratio blends)

\section{SN Applied Sciences}


Figure 5 shows a SEM micrograph of the nonwoven mat after sodium carbonate treatment. Obviously, the surface structural appearance of the mat has changed. The sodium carbonate treatment appears to result in a loss of well-defined nanofiber structure. This behavior has been previously reported by other authors [45, 46]. The change in appearance is believed to be a consequence of a dissolution of the amine salts formed by the chitosan and its solvent $\left(\mathrm{NH}_{3}{ }^{+} \mathrm{CH}_{3} \mathrm{COO}^{-}\right.$in our case) which cause the whole structure collapse.

Figure 6a shows a typical EDX spectrum for a CS/PEO nanofibrous mat sample after copper ions adsorption. A copper peak is observed indicating the existence of copper ions. The sulfur peak appears due to the copper sulfate used to prepare the copper solutions for the adsorption trials. Figure $6 \mathrm{~b}$ also presents a typical EDX mapping of the copper loaded CS-PEO mat that clearly shows the homogenous distribution of sorbed copper.

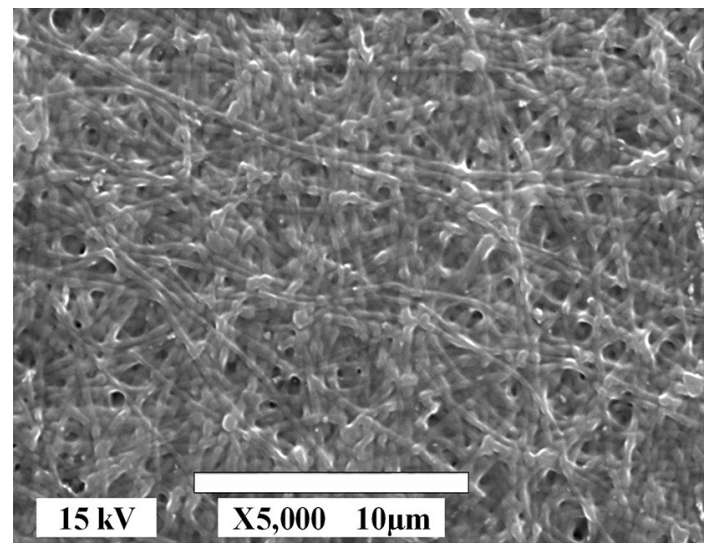

Fig. 5 SEM image of collapsed nanofibers after washing with $\mathrm{Na}_{2} \mathrm{CO}_{3}$

\subsection{Copper adsorption kinetics}

The effect of contact time on $\mathrm{Cu}^{2+}$ sorption capacity is presented in Fig. 7. Results show that the adsorption rate was fast in the initial stages of the process, where most of the adsorption occurs in approximately the first $30 \mathrm{~min}$. The rate gradually decreased later on the way towards equilibrium where the maximum adsorption is achieved within $150 \mathrm{~min}(96 \mathrm{mg} / \mathrm{g})$ and the adsorption capacity does not change anymore with time. This means that all the available sites of adsorbent are saturated. For that reason, for further analysis, $150 \mathrm{~min}$ is established as equilibrium time of copper sorption.

Three reaction models were used to interpret experimental data: Pseudo-first order, pseudo-second order and intraparticle diffusion models. The kinetic parameters for all models were obtained by using OriginPro 8.5.1 software, and results are presented in Table 3. As it can be seen, the intraparticle diffusion model presents low $R^{2}$ value, demonstrating that this model is poorly involved in the rate of adsorption. On the contrary, both pseudofirst order and pseudo-second order models resulted in high $R^{2}$ values. This suggests that the rate-limiting step of $\mathrm{Cu}^{2+}$ ions depends on both chemical and physical adsorption. A similar behavior was observed by other authors [13, $31,46,47]$. However, according to the literature [31, 48], the plots of the first-order equation are only suitable in the first stage (20-30 $\mathrm{min}$ ) of interaction and not for the entire range of contact times. Chitosan is actually well known for binding metal ions to the nanofibers surface via a chelation process by exchanging electron pairs with amino groups. Copper adsorption pathways can usually be divided into the "bridge model" [49] and the "pendant model" [50]. Briefly, the bridge model assumes that the metal ion is bound by many nitrogen and oxygen atoms from the same molecular chain or from separate chains. On
Fig. 6 A typical energy dispersive a spectrum of $\mathrm{Cu}$ (II) ions loaded with CS-PEO; b mapping image showing the distribution of copper signals on the surface
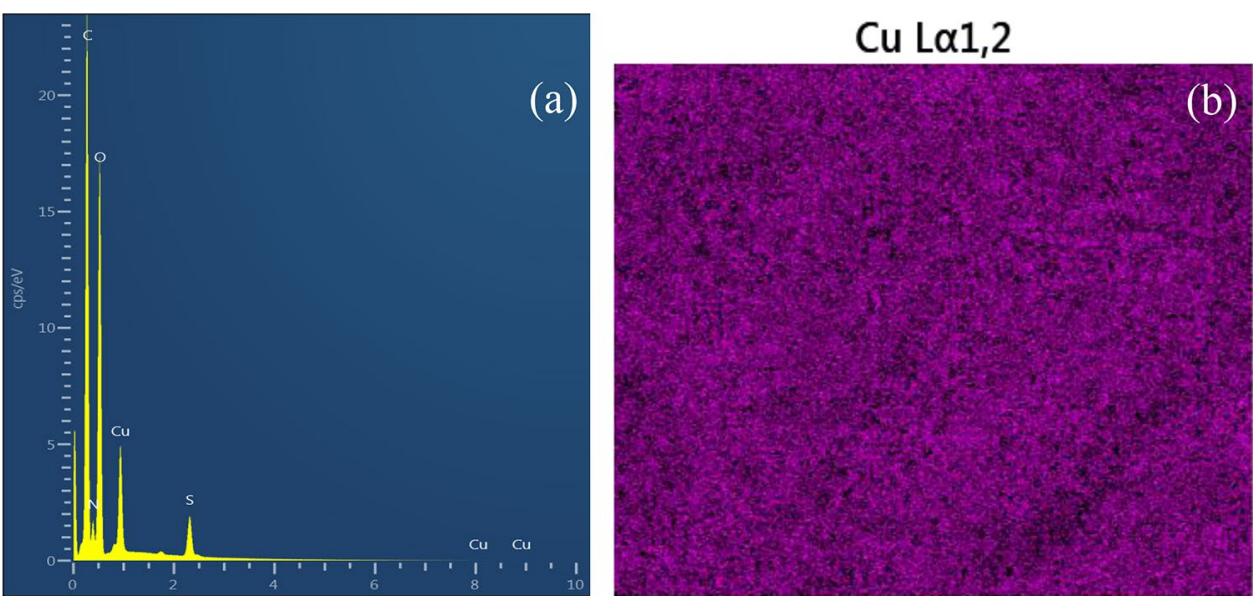

SN Applied Sciences A SPRINGER NATURE journal 

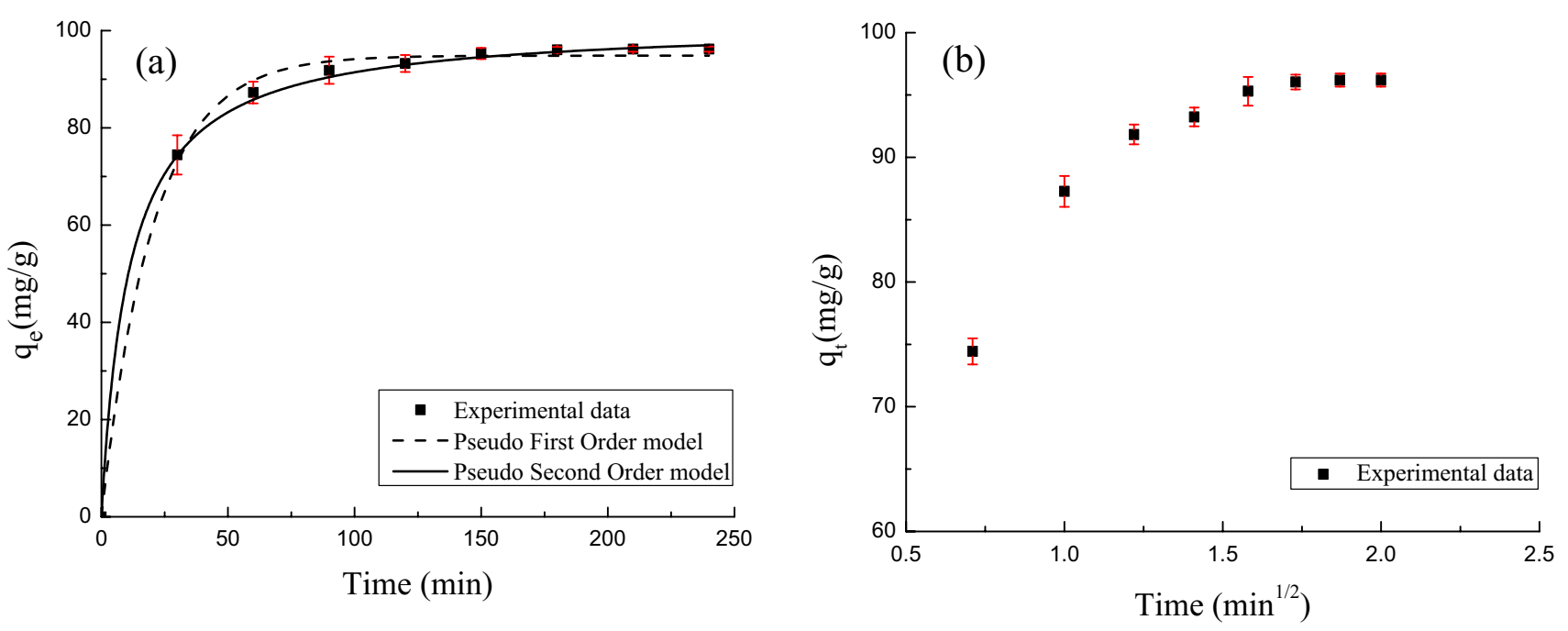

Fig. 7 a Pseudo-first and pseudo-second order and $\mathbf{b}$ intraparticle diffusion kinetic models for adsorption of copper ions onto the CS/PEO electrospun mat at room temperature

Table 3 Summary of kinetic models' parameters for the adsorption of copper ions onto CS/PEO nanofibrous mats

\begin{tabular}{|c|c|c|c|c|c|c|c|c|c|}
\hline \multirow{2}{*}{$\begin{array}{l}\text { Experimental } \\
q_{\text {exp }}(\mathrm{mg} / \mathrm{g})\end{array}$} & \multicolumn{3}{|c|}{ Pseudo first order model } & \multicolumn{3}{|c|}{ Pseudo second order model } & \multicolumn{3}{|c|}{$\begin{array}{l}\text { Intraparticle diffusion } \\
\text { model }\end{array}$} \\
\hline & $k_{1}\left(\min ^{-1}\right)$ & $q_{e}(\mathrm{mg} / \mathrm{g})$ & $\mathrm{R}^{2}$ & $k_{2}(g / g \min )$ & $q_{e}(\mathrm{mg} / \mathrm{g})$ & $\mathrm{R}^{2}$ & $k_{\text {id }}$ & $\mathrm{C}$ & $\mathrm{R}^{2}$ \\
\hline 0.19 & 0.0488 & 94.85 & 0.9975 & 0.0009 & 101.40 & 0.9995 & 42.666 & 26.507 & 0.15 \\
\hline
\end{tabular}

the contrary, the pendant model assumes that the metal ion is bound by only one nitrogen atom.

\subsection{Adsorption isotherms and thermodynamic parameters}

Figure 8 shows Langmuir, Freundlich and Dubinin-Radushkevich isotherms nonlinear model fittings at $25^{\circ} \mathrm{C}$, $45^{\circ} \mathrm{C}$ and $60^{\circ} \mathrm{C}$, respectively. Table 4 presents the values of corresponding isotherm parameters, including the correlation coefficients $\left(R^{2}\right)$ of each model. As it can be seen, the curves have an L-shape (Langmuir) type, in which the curves are concave upwards; it takes into account that the higher the solute concentration, the greater the adsorption capacity until the adsorbent becomes covered [48, 51]. Results show that copper adsorption slightly increases with temperature, which suggest that the rise of temperature favors the adsorption efficiency of copper ions.

The correlation coefficient parameters demonstrate that Langmuir isotherm model is best fitting experimental data with $R^{2}$ values ranging from 0.98 to 0.99 . Freundlich isotherm is also fitting data correctly with $R^{2}$ values slightly lowered than values for Langmuir. Such closed correlation coefficients suggest that both monolayer sorption and heterogeneous surface conditions may coexist under these experimental conditions. D-R isotherm was the least appropriate model to describe experimental data with the lowest $R^{2}$ values at every temperature studied. Since Langmuir isotherm is best fitting experimental data; it is then possible to determine the feasibility of the adsorption process using the dimensionless constant separation factor $\left(R_{L}\right)$ which is specified as [52]:

$R_{L}=\frac{1}{1+K_{L} C_{0}}$

where $C_{0}(\mathrm{mg} / \mathrm{L})$ is the initial copper ions concentration. The value of $R_{L}$ indicates the type of isotherm that is either unfavorable $\left(R_{L}>1\right)$, linear $\left(R_{L}=1\right)$, favorable to chemisorption $\left(0<R_{L}<1\right)$ or irreversible $\left(R_{L}=0\right)$. In this study, the value of $R_{L}$ for copper sorption by CS-PEO mat varied from 0.0805 to 0.7283 . Therefore, this result indicates the favorability of the copper ion sorption on the current adsorbent.

Regarding the D-R model, the calculated free adsorption energy for adsorption $(E)$ was below $8 \mathrm{~kJ} / \mathrm{mol}$ for all temperature studied as can be seen in Table 4. These results indicate that the adsorption mechanism of copper ions by the nanofiber mat is rather physical. However, the $D-R$ model does not fit the data well with the lowest $R^{2}$ values compared to Langmuir and Freundlich models.

Thermodynamic parameters such as the Gibbs free energy, enthalpy change, and entropy change are 

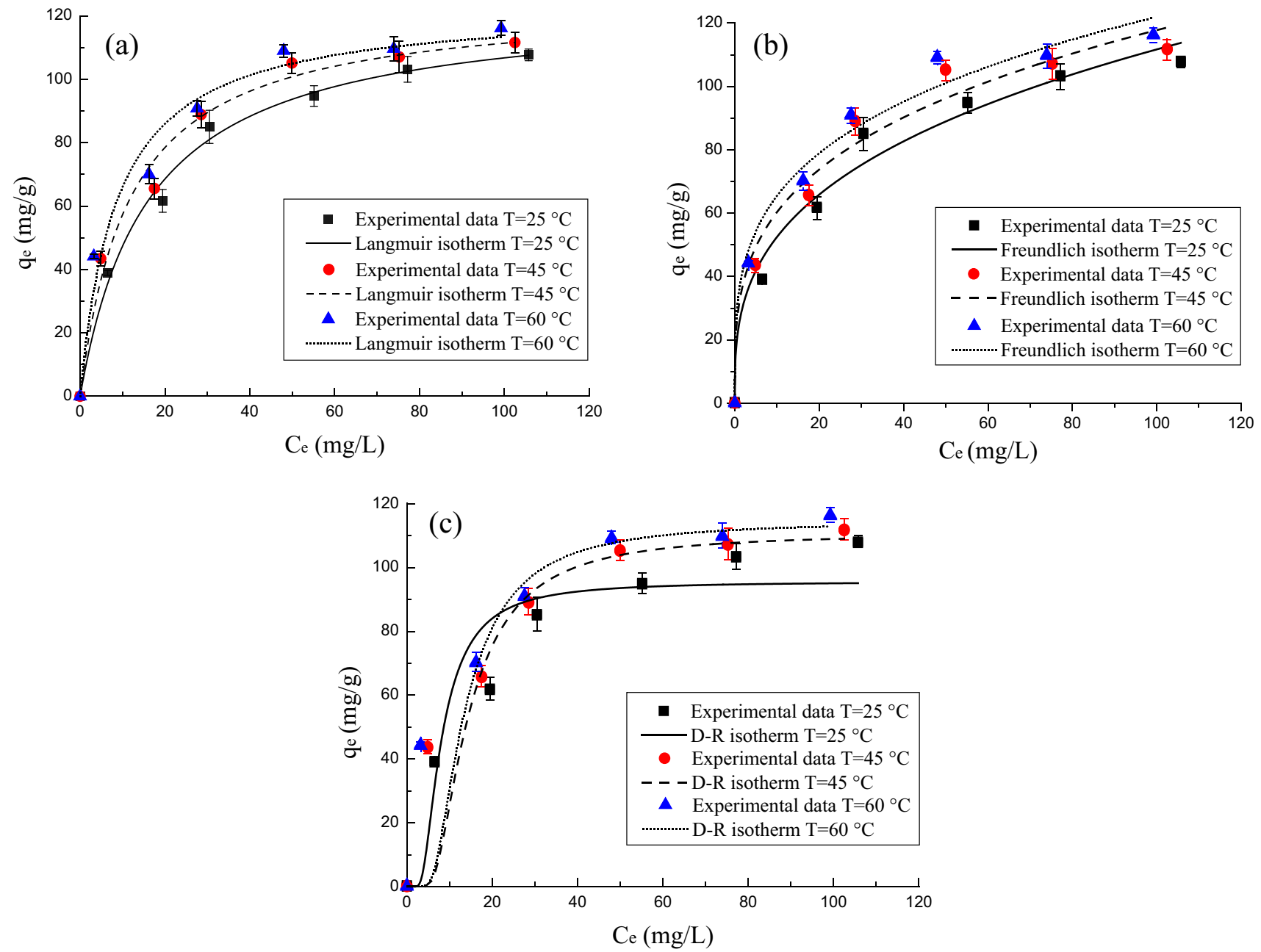

Fig. 8 Non-linear fitting of experimental data by a Langmuir, b Freundlich, and $\mathbf{c}$ Dubinin-Radushkevich isotherm models at $25^{\circ} \mathrm{C}, 45^{\circ} \mathrm{C}$ and $60^{\circ} \mathrm{C}$

Table 4 The three isotherms model parameters for metal adsorption onto CS-PEO adsorbent

\begin{tabular}{|c|c|c|c|c|c|c|c|c|c|c|}
\hline \multirow[t]{2}{*}{$T\left({ }^{\circ} \mathrm{C}\right)$} & \multicolumn{3}{|l|}{ Freundlich } & \multicolumn{3}{|l|}{ Langmuir } & \multicolumn{4}{|l|}{$D-R$} \\
\hline & $K_{F}(\mathrm{mg} / \mathrm{g})$ & $n$ & $\mathrm{R}^{2}$ & $q_{\max }(\mathrm{mg} / \mathrm{g})$ & $K_{L}(\mathrm{~L} / \mathrm{mg})$ & $\mathrm{R}^{2}$ & $q_{D R}(\mathrm{mg} / \mathrm{g})$ & $\beta_{D R}\left(\mathrm{~mol}^{2} / \mathrm{J}^{2}\right)$ & $E(\mathrm{~kJ} / \mathrm{mol})$ & $\mathrm{R}^{2}$ \\
\hline 25 & 24.361 & 3.032 & 0.9756 & 124.01 & 0.061 & 0.9914 & 95.56 & $8.8 \mathrm{E}-06$ & 0.238 & 0.8980 \\
\hline 45 & 30.581 & 3.424 & 0.9719 & 124.41 & 0.085 & 0.9823 & 110.69 & $2.6 \mathrm{E}-05$ & 0.138 & 0.7790 \\
\hline 60 & 34.779 & 3.680 & 0.9802 & 125.16 & 0.115 & 0.9802 & 114.51 & $2.3 \mathrm{E}-05$ & 0.145 & 0.7808 \\
\hline
\end{tabular}

provided in Table 5. The negative values of $\Delta G^{\circ}$ for all temperatures indicate as expected a spontaneous process and thermodynamically favorable.

Furthermore, the numerical value of $\Delta G^{\circ}$ was more negative when the temperature increment. This indicates that the $\mathrm{Cu}^{2+}$ sorption is more spontaneous at higher temperature, suggesting that the quantity adsorbed at equilibrium increased with increasing temperature. The positive value of $\Delta H^{\circ}$ is a proof of the endothermic nature of the sorption process. One possible interpretation of this in
Table 5 Parameters acquired from the adsorption data thermodynamic analysis

\begin{tabular}{lrlll}
\hline$T\left({ }^{\circ} \mathrm{C}\right)$ & \multicolumn{1}{c}{$K_{c}$} & $\Delta G^{\circ}(\mathrm{kJ} / \mathrm{mol})$ & $\Delta H^{\circ}(\mathrm{kJ} / \mathrm{mol})$ & $\Delta S^{\circ}(\mathrm{kJ} / \mathrm{mol} \mathrm{K})$ \\
\hline 25 & 8.11 & -5.19 & 17.66 & 0.07 \\
45 & 12.07 & -6.69 & & \\
60 & 18.16 & -8.03 & & \\
\hline
\end{tabular}


terms of enthalpy is that ions such as Cu (II) are completely solvated in water. When these copper ions are about to be adsorbed, a part of their hydration sheath must be lost, which requires energy [23]. This dehydration energy replaces the exothermic degree of the copper ions being tied to the surface. The value of $\Delta S^{\circ}$ comes out as positive, showing that after the adsorption process of $\mathrm{Cu}^{2+}$ ions, more randomness is generated at the solid-solution interface during the adsorption. The positive entropy also suggests that the adsorption process is irreversible $[53,54]$.

\subsection{Desorption studies}

To date, the desorption of heavy metals from chitosan sorbent materials has not been widely investigated. There is thus a need to develop suitable approaches to supply chitosan sorbent materials with reusability feature. At present, solutions of $\mathrm{H}_{2} \mathrm{SO}_{4}, \mathrm{HCl}, \mathrm{NaCl}, \mathrm{EDTA}, \mathrm{HNO}_{3}$ and $\mathrm{NaOH}$ as eluents have been used for the desorption process of copper from chitosan-based materials. However, so far there are no publications with a complete or high percentage of desorption at good conditions. For example, Rajurkar and Mahajan [55] examined the effect of $\mathrm{NaOH}$ $0.1 \mathrm{M}$ on $\mathrm{Cu}^{2+}$ desorption from chitosan nonwoven mat, and only $84.9 \%$ desorption efficiency was achieved after $90 \mathrm{~min}$. In another study [56], two different eluents (EDTA and $\mathrm{HNO}_{3}$ solutions) were used for desorption of copper from chitosan/PVA beads. The maximum desorption was $87.4 \%$ for $0.001 \mathrm{M}$ EDTA and $68.5 \%$ for $0.001 \mathrm{M} \mathrm{HNO}_{3}$. In the work of Ghaee et al. [6], desorption of $\mathrm{Cu}^{2+}$ from a chitosan membrane has been performed with EDTA $0.0004 \mathrm{M}$. Desorption reached $77.4 \%$ after $24 \mathrm{~h}$. Many other works [1, $2,19,43$ ] reported very high desorption capacities (above 94\%). However, information was incomplete regarding the time to achieve the maximum desorption and/or weight loss issues of the nanofiber mat, which are two very important factors at industrial scale. Therefore, in this work, the desorption of copper ions from the CS/PEO electrospun nanofibrous mat was carried out by testing five different eluents using conditions previously optimized trying out different concentrations, agitation speed, contact time and temperature. The results are shown in Fig. 9.

Figure 9 shows that desorption is not only poor in acidic medium but also the nanofibers are damaged, leading to significant weight losses of the nanofibrous mats. This is because in such medium, the dissolution of chitosan occurs, except in sulfuric acid solutions, where chitosan is insoluble. However, $\mathrm{H}_{2} \mathrm{SO}_{4}$ treated mat was not capable of adsorbing more than $10 \%$.

It is well known that copper ions can be desorbed properly and efficiently by EDTA solutions which is a chelating agent who has the strong ability to form a stable complex with copper. On the other hand, the mat's structural property is affected at high concentrations of EDTA due to the low pH of the solution. However, it can be seen that high desorption without significant weight losses can be achieved using alkaline EDTA $0.001 \mathrm{M}$ as the eluent (EDTA$\mathrm{NaOH}, \mathrm{pH}$ 8) with only $1 \mathrm{~h}$ contact time. Based on these results, $\mathrm{pH}$ values were adjusted by varying the volume of $\mathrm{NaOH} 0.01 \mathrm{M}$ in the EDTA-NaOH solution in order to optimize the regeneration of the nanofibrous mat (Fig. 10).

Figure 10 shows that desorption efficiency increases with $\mathrm{pH}$. This is because under an alkaline environment, the electrostatic interactions between the CS-PEO mat and copper ions are weakened, which improves copper desorption from the mat [23]. When $\mathrm{pH}$ was equal to or higher than 8.5, the desorption efficiency remained almost constant at the highest value of $98.7 \%$. Therefore, a pH of 8.5 was suitable for the desorption of copper ions.

An EDX analysis of the mat was also carried out to determine the elemental composition of the nanofibrous mat after each processing step (Table 6). It is obvious that the
Fig. 9 Weight losses of the nanofibrous mats and desorption performances of various eluents

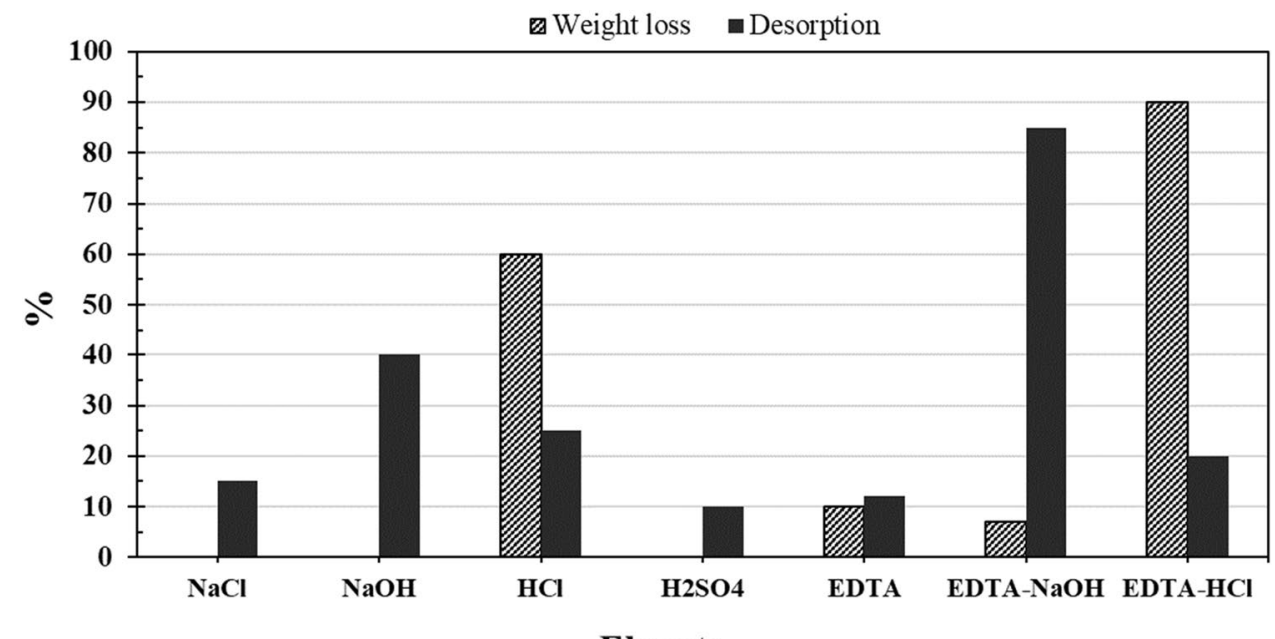

Eluents 
Fig. 10 Effect of $\mathrm{pH}$ on $\mathrm{Cu}$ (II) desorption efficiency and weight loss of the mat

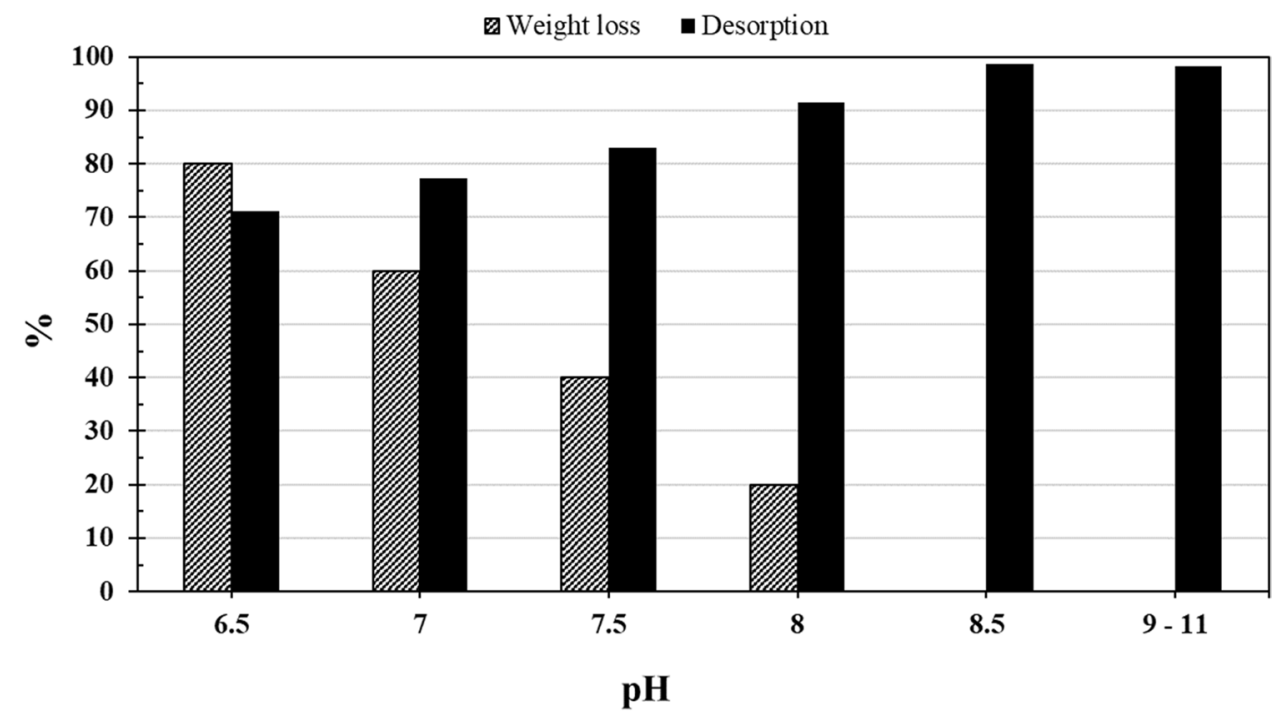

Table 6 Surface composition (\%Atm) of CS-PEO nanofibers determined by EDX

\begin{tabular}{lllll}
\hline Element & Native CS-PEO & $\begin{array}{l}\text { Neutral- } \\
\text { ized CS- } \\
\text { PEO }\end{array}$ & Adsorption & Desorption \\
\hline $\mathrm{C}$ & 68.41 & 61.39 & 52.43 & 59.83 \\
$\mathrm{O}$ & 26.40 & 31.92 & 36.73 & 32.70 \\
$\mathrm{~N}$ & 5.19 & 6.69 & 6.72 & 7.38 \\
$\mathrm{Cu}$ & - & - & 2.29 & 0.09 \\
$\mathrm{~S}$ & - & - & 1.83 & - \\
$\mathrm{Na}$ & - & - & - & - \\
\hline
\end{tabular}

adsorption and desorption processes occur as copper and sulfur ions appear and then disappear, respectively. On the other hand, results reveal that washing of the mat after the stabilization treatment was efficient since no sodium peak appears in the EDX spectrum.

\subsection{Reusability potential of the nanofibrous mats}

The regeneration of nanofibrous mat is a critical aspect in the adsorption process, as the reusability capacity is an important issue for economic improvement, especially on an industrial scale. Thus, multiple adsorption/ desorption cycles are used to evaluate the performance of the adsorbent's reusability and metal recovery. As can be seen in Fig. 11, the adsorption capacity of the nanofibrous mat was slightly reduced after five adsorption/ desorption cycles. Results demonstrate that the CS/PEO nanofibers can be reused several times without major loss of the adsorption efficiency. This is therefore opening important opportunities for industrial applications.
Fig. 11 Reusability performance of regenerated CS-PEO nanofibrous mats at optimized conditions

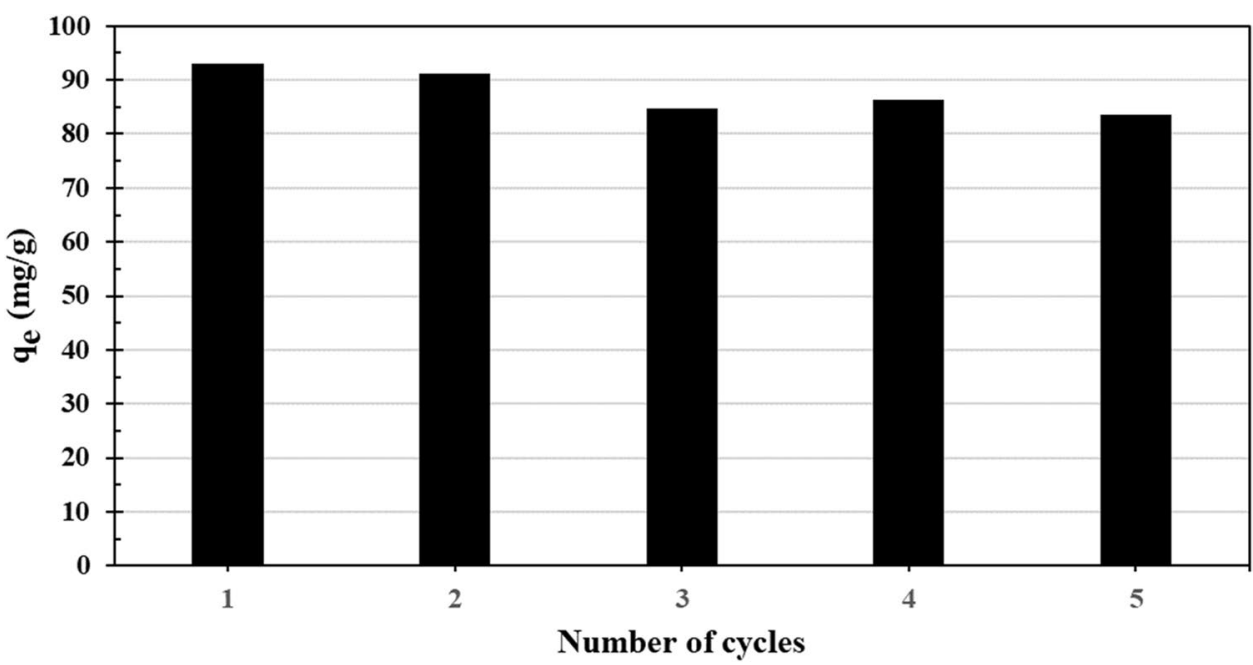

SN Applied Sciences A SPRINGER NATURE journa 


\section{Conclusions}

The feasibility of the preparation of CS-PEO nanofibrous mat by using a new electrospinning collector design has been demonstrated in this paper. It has also been shown that the performance characteristics of the nonwoven mat are comparable to those made by using the typical electrospinning set-up mostly used in experimental studies. This device does not only provide time-saving optimization of the parameters, reusability, easy recovery of the nonwoven mat and high performance, but is also very simple to make. This combination of advantages reveals the potential of this new design and provides better options for future works. Besides, it could be applied well on an industrial scale. Beyond that, the CS-PEO nonwoven mats obtained showed a high adsorption capacity towards copper ions in aqueous solutions. The metal adsorption on the CS-PEO mat slightly increased as the temperature increased. Three isotherm models were used to interpret the equilibrium data, with the Langmuir model giving the best fit. The mean free energy values determined from the D-R model showed that the mechanism of adsorption was rather physical. However, according to the kinetic results, both physical and chemical mechanisms are involved in the adsorption process. The copper adsorption process onto the CS-PEO composite sorbent was spontaneous $\left(\Delta G^{\circ}<0\right)$ and endothermic $\left(\Delta H^{\circ}>0\right)$. This eco-friendly material is a promising adsorbent to replace activated carbon due to its adsorption capacity and to the abundance and availability of waste products used to make them. One particular advantage of the sorbent material is its remarkable reusability potential showed by successive adsorption-desorption cycles, making it suitable for use in water purification. Based on results obtained, it can be concluded that CS-PEO nanofibrous mats produced using a wire-frame collector can be used efficiently as an adsorbent to remove copper ions from wastewater.

Acknowledgements The authors gratefully acknowledge Natural Science and Engineering Research Council of Canada (Grant No. RGPIN2016-04844), Mitacs Globalink Program (Grant No. GLF181) and La Fondation UQTR for the financial support.

\section{Compliance with ethical standards}

Conflict of interest The authors have no conflict of interest to declare.

\section{References}

1. Tetala KKR, Stamatialis DF (2013) Mixed matrix membranes for efficient adsorption of copper ions from aqueous solutions.
Sep Purif Technol 104:214-220. https://doi.org/10.1016/j. seppur.2012.11.022

2. Kampalanonwat P, Supaphol P (2010) Preparation and adsorption behavior of aminated electrospun polyacrylonitrile nanofiber mats for heavy metal ion removal. ACS Appl Mater Interfaces 2:3619-3627. https://doi.org/10.1021/am1008024

3. Sehaqui $\mathrm{H}$, de Larraya UP, Liu P et al (2014) Enhancing adsorption of heavy metal ions onto biobased nanofibers from waste pulp residues for application in wastewater treatment. Cellulose 21:2831-2844. https://doi.org/10.1007/s1057 0-014-0310-7

4. Lakhdhar I, Mangin P, Chabot B (2015) Copper (II) ions adsorption from aqueous solutions using electrospun chitosan/peo nanofibres: Effects of process variables and process optimization. J Water Process Eng 7:295-305. https://doi.org/10.1016/j. jwpe.2015.07.004

5. Aung KT, Hong S, Park S, Lee C (2020) Applied sciences removal of CU ( II ) from aqueous solutions using amine-doped polyacrylonitrile fibers. Appl Sci 1738:1-12. https://doi.org/10.3390/ app10051738

6. Ghaee A, Shariaty-Niassar M, Barzin J, Matsuura T (2010) Effects of chitosan membrane morphology on copper ion adsorption. Chem Eng J 165:46-55. https://doi.org/10.1016/j. cej.2010.08.051

7. Dragan E, Apopei Loghin DF, Cocarta Al (2014) Efficient sorption of $\mathrm{Cu}^{2+}$ by composite chelating sorbents based on potato starch-graft-polyamidoxime embedded in chitosan beads. ACS Appl Mater Interfaces 6:16577-16592. https://doi.org/10.1021/ am504480q

8. Yang J, Hou B, Wang J et al (2019) Nanomaterials for the removal of heavy metals from wastewater. Nanomaterials. https://doi. org/10.3390/nano9030424

9. Xiao S, Ma H, Shen $M$ et al (2011) Excellent copper(II) removal using zero-valent iron nanoparticle-immobilized hybrid electrospun polymer nanofibrous mats. Colloids Surf A Physicochem Eng Asp 381:48-54. https://doi.org/10.1016/j.colsu rfa.2011.03.005

10. Wang LK, Wang M-S, Hung Y et al (2017) Handbook of advanced industrial and hazardous wastes management. CRC Press, Boca Raton

11. Sahu S, Mallik L, Pahi S et al (2020) Facile synthesis of poly o-toluidine modified lanthanum phosphate nanocomposite as a superior adsorbent for selective fluoride removal: a mechanistic and kinetic study. Chemosphere. https://doi.org/10.1016/j.chemo sphere.2020.126551

12. Schimmel D, Fagnani KC, Dos Santos JBO et al (2010) Adsorption of turquoise blue qg reactive dye on commercial activated carbon in batch reactor: kinetic and equilibrium studies. Braz J Chem Eng 27:289-298. https://doi.org/10.1590/S0104-66322 010000200007

13. Sahu UK, Sahu S, Mahapatra SS, Patel RK (2017) Cigarette soot activated carbon modified with $\mathrm{Fe}_{3} \mathrm{O}_{4}$ nanoparticles as an effective adsorbent for $\mathrm{As}(\mathrm{III})$ and $\mathrm{As}(\mathrm{V})$ : Material preparation, characterization and adsorption mechanism study. J Mol Liq 243:395-405. https://doi.org/10.1016/j.molliq.2017.08.055

14. Ding F, Nie Z, Deng $\mathrm{H}$ et al (2013) Antibacterial hydrogel coating by electrophoretic co-deposition of chitosan/alkynyl chitosan. Carbohydr Polym 98:1547-1552. https://doi.org/10.1016/j.carbp ol.2013.07.042

15. Chen J, Zhan Y, Wang Y et al (2018) Chitosan/silk fibroin modified nanofibrous patches with mesenchymal stem cells prevent heart remodeling post-myocardial infarction in rats. Acta Biomater 80:154-168. https://doi.org/10.1016/j.actbio.2018.09.013

16. Kołodyńska D (2012) Adsorption characteristics of chitosan modified by chelating agents of a new generation. Chem Eng J 179:33-43. https://doi.org/10.1016/j.cej.2011.10.028 
17. Abdul Khalil HP, Sab Chaturbhuj K, Saurabha Adnan AS et al (2016) A review on chitosan-cellulose blends and nanocellulose reinforced chitosan biocomposites: properties and their applications. Carbohydr Polym 150:216-226. https://doi.org/10.1016/j. carbpol.2016.05.028

18. Muthu Kumar TS, Senthil Kumar K, Rajini N et al (2019) A comprehensive review of electrospun nanofibers: food and packaging perspective. Compos B Eng 175:107074. https://doi. org/10.1016/j.compositesb.2019.107074

19. Nthumbi RM, Ngila JC, Kindness A et al (2011) Method development for flow adsorption and removal of lead and copper in contaminated water using electrospun nanofibers of chitosan blend. Anal Lett 44:1937-1955. https://doi.org/10.1080/00032 719.2010 .539737

20. Haider A, Haider S, Kang I (2015) REVIEW A comprehensive review summarizing the effect of electrospinning parameters and potential applications of nanofibers in biomedical and biotechnology. Arab J Chem. https://doi.org/10.1016/j.arabj c.2015.11.015

21. Ding B, Wang X, Yu J (2019) Electrospinning: nanofabrication and applications. Matthew Dean, Amsterdam

22. Alghoraibi I, Alomari S (2019) Different methods for nanofiber design and fabrication. In: Barhoum A et al (eds) Handbook of nanofibers. Springer, Damascus

23. Zhang Y, Lin S, Qiao J et al (2018) Malic acid-enhanced chitosan hydrogel beads (mCHBs) for the removal of $\mathrm{Cr}(\mathrm{VI})$ and $\mathrm{Cu}(\mathrm{II})$ from aqueous solution. Chem Eng J 353:225-236. https://doi. org/10.1016/j.cej.2018.06.143

24. Wang D, Cheng W, Yue $Y$ et al (2018) Electrospun cellulose nanocrystals/chitosan/polyvinyl alcohol nanofibrous films and their exploration to metal ions adsorption. Polymers (Basel). https://doi.org/10.3390/polym10101046

25. Qasim SB, Najeeb S, Delaine-Smith RM et al (2017) Potential of electrospun chitosan fibers as a surface layer in functionally graded GTR membrane for periodontal regeneration. Dent Mater 33:71-83. https://doi.org/10.1016/j.dental.2016.10.003

26. Arkoun M, Daigle F, Heuzey MC, Ajji A (2017) Antibacterial electrospun chitosan-based nanofibers: A bacterial membrane perforator. Food Sci Nutr 5:865-874. https://doi.org/10.1002/ fsn3.468

27. Haider S, Park SY (2009) Preparation of the electrospun chitosan nanofibers and their applications to the adsorption of $\mathrm{Cu}(\mathrm{II})$ and $\mathrm{Pb}$ (II) ions from an aqueous solution. J Memb Sci 328:90-96. https://doi.org/10.1016/j.memsci.2008.11.046

28. Ohkawa K, Cha D, Kim H et al (2004) Electrospinning of chitosan. Macromol Rapid Commun 25:1600-1605. https://doi. org/10.1002/marc.200400253

29. Pakravan M, Heuzey MC, Ajji A (2011) A fundamental study of chitosan/PEO electrospinning. Polymer (Guildf) 52:4813-4824. https://doi.org/10.1016/j.polymer.2011.08.034

30. Yuan TT, Jenkins PM, Digeorge Foushee AM et al (2016) Electrospun chitosan/polyethylene oxide nanofibrous scaffolds with potential antibacterial wound dressing applications. J Nanomater. https://doi.org/10.1155/2016/6231040

31. Lakhdhar I, Belosinschi D, Mangin P, Chabot B (2016) Development of a bio-based sorbent media for the removal of nickel ions from aqueous solutions. J Environ Chem Eng 4:3159-3169. https://doi.org/10.1016/j.jece.2016.06.026

32. Abràmoff MD, Magalhães PJ, Ram SJ (2004) Image processing with image. J Biophotonics Int 11:36-41. https://doi. org/10.1201/9781420005615.ax4

33. Guibal E (2004) Interactions of metal ions with chitosan-based sorbents: a review. Sep Purif Technol 38:43-74. https://doi. org/10.1016/j.seppur.2003.10.004

34. Bermejo-Barrera A, Bermejo-Barrera $P$, Bermejo Martinez $F$ (1985) Simultaneous determination of copper and cobalt with
EDTA using derivative spectrophotometry. Analyst 110:13131315. https://doi.org/10.1039/AN9851001313

35. Nthumbi RM, Catherine Ngila J, Moodley B et al (2012) Application of chitosan/polyacrylamide nanofibres for removal of chromate and phosphate in water. Phys Chem Earth 50-52:243-251. https://doi.org/10.1016/j.pce.2012.07.001

36. Hamdaoui O (2006) Batch study of liquid-phase adsorption of methylene blue using cedar sawdust and crushed brick. J Hazard Mater 135:264-273. https://doi.org/10.1016/j.jhazm at.2005.11.062

37. Weber WJ, Morris JC (1963) Kinetics of adsorption on carbon from solution. J Sanit Eng Div 89:31-60

38. Langmuir I (1916) The constitution and fundamental properties of solids and liquids. J Am Chem Soc 38:2221-2295. https://doi. org/10.1021/ja02268a002

39. Freundlich H (1906) Über die Adsorption in Lösungen. Z Phys Chem 57:385-470. https://doi.org/10.1515/zpch-1907-5723

40. Dubinin M, Zaverina ED, Radushkevich LV (1947) Sorption and structure of active carbons I. Adsorption of organic vapors. Zhurnal Fiz Khimii 21:1351-1362. https://doi.org/10.1007/BF011 67331

41. Sahu UK, Sahu S, Mahapatra SS, Patel RK (2019) Synthesis and characterization of magnetic bio-adsorbent developed from Aegle marmelos leaves for removal of $\mathrm{As}(\mathrm{V})$ from aqueous solutions. Environ Sci Pollut Res 26:946-958. https://doi. org/10.1007/s11356-018-3643-1

42. Sahu S, Pahi S, Sahu JK et al (2020) Kendu (Diospyros melanoxyIon Roxb) fruit peel activated carbon-an efficient bioadsorbent for methylene blue dye: equilibrium, kinetic, and thermodynamic study. Environ Sci Pollut Res 27:22579-22592. https:// doi.org/10.1007/s11356-020-08561-2

43. Lisha KP, Maliyekkal SM, Pradeep T (2010) Manganese dioxide nanowhiskers: a potential adsorbent for the removal of $\mathrm{Hg}$ (II) from water. Chem Eng J 160:432-439. https://doi.org/10.1016/j. cej.2010.03.031

44. Gregg SJ, Sing KSW (1982) Adsorption, surface area and porosity. Academic Press, New York

45. Salihu G, Goswami P, Russell S (2012) Hybrid electrospun nonwovens from chitosan/cellulose acetate. Cellulose 19:739-749. https://doi.org/10.1007/s10570-012-9666-8

46. Phan D-N, Lee $H$, Huang B et al (2018) Fabrication of electrospun chitosan/cellulose nanofibers having adsorption property with enhanced mechanical property. Cellulose 26:1781-1793. https ://doi.org/10.1007/s10570-018-2169-5

47. Aliabadi M, Irani M, Ismaeili J et al (2013) Electrospun nanofiber membrane of PEO/Chitosan for the adsorption of nickel, cadmium, lead and copper ions from aqueous solution. Chem Eng J 220:237-243. https://doi.org/10.1016/j.cej.2013.01.021

48. Gerente C, Lee VKC, Le Cloirec P, McKay G (2007) Application of chitosan for the removal of metals from wastewaters by adsorption-mechanisms and models review. Crit Rev Environ Sci Technol 37:41-127. https://doi.org/10.1080/1064338060 0729089

49. Yaku F, Muraki E, Tsushiya K et al (1977) Chitosan-metal complexes and their function. Cell Chem Technol 11:105-113

50. Ogawa K, Inukai S (1987) X-ray diffraction study of sulfuric, nitric, and halogen acid salts of chitosan. Carbohydr Res 160:425-433. https://doi.org/10.1016/0008-6215(87)80328-2

51. Giles CH, Smith D, Huitson A (1974) A General treatment and classification of the solute adsorption isotherm. J Colloid Interface Sci 47:755-765. https://doi.org/10.1016/00219797(74)90252-5

52. Hall KR, Eagleton LC, Acrivos A, Vermeulen T (1966) Pore- and solid-diffusion kinetics in fixed-bed adsorption under constantpattern conditions. Ind Eng Chem Fundam 5:212-223. https:// doi.org/10.1021/i160018a011 
53. Karapinar N, Donat R (2009) Adsorption behaviour of $\mathrm{Cu}^{2+}$ and $\mathrm{Cd}^{2+}$ onto natural bentonite. Desalination 249:123-129. https:// doi.org/10.1016/j.desal.2008.12.046

54. Donat R, Akdogan A, Erdem E, Cetisli H (2005) Thermodynamics of $\mathrm{Pb}^{2+}$ and $\mathrm{Ni}^{2+}$ adsorption onto natural bentonite from aqueous solutions. J Colloid Interface Sci 286:43-52. https://doi. org/10.1016/j.jcis.2005.01.045

55. Rajurkar NS, Mahajan D (2015) Removal and recovery of copper ions using chitosan as an adsorbent. J Appl Chem 4:1206-1217

56. Wan Ngah WS, Kamari A, Koay YJ (2004) Equilibrium and kinetics studies of adsorption of copper (II) on chitosan and
chitosan/PVA beads. Int J Biol Macromol 34:155-161. https:// doi.org/10.1016/j.ijbiomac.2004.03.001

Publisher's Note Springer Nature remains neutral with regard to jurisdictional claims in published maps and institutional affiliations. 